\title{
Coupling soil water and shoot dynamics in three grass species: A spatial stochastic model on water competition in Neotropical savanna
}

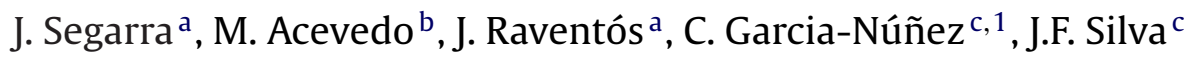 \\ a Dpto Ecología, Universidad de Alicante, Alicante, Spain \\ b Electrical Engineering Department, P.O. Box 310440, University of North Texas, Denton, TX 76203, USA \\ ${ }^{\mathrm{c}}$ Instituto de Ciencias Ambientales y Ecológicas (ICAE), Universidad de los Andes, Mérida, Venezuela
}

\section{A R T I C L E I N F O}

\section{Article history:}

Received 16 March 2009

Received in revised form 22 June 2009

Accepted 26 June 2009

Available online 3 August 2009

\section{Keywords:}

Savanna

Stochastic modelling

Phenology

Water competition

\begin{abstract}
A B S T R A C T
Savannas are ecosystems known for their high environmental and economic value. They cover at least $20 \%$ of the global land surface and, in some cases, can act as a boundary between tropical rainforest and deserts. Water is an important determinant of savanna ecosystems.

In this paper, we present a theoretical stochastic model of root competition for water, which couples, soil water availability, phenology, and root and shoot architecture applied to three Neotropical savanna grasses. Soil moisture was simulated using a daily balance, as proposed by Rodriguez-Iturbe et al. [Rodriguez-Iturbe, I., Porporato, A., Ridolfi, L., Isham, V., Cox, D.R., 1999. Probabilistic modelling of water balance at a point: the role of climate, soil and vegetation. Proc. R. Soc. London, Ser. A 455, 3789-3805.]. To simulate rainfall stochasticity, we used daily precipitation data from the airport weather station in the State of Barinas, Venezuela, for the period 1991-2007. Competition among neighbouring plants took into account the spatial distribution of the individuals. As a final step, the model allowed us to calculate the shoot dynamic of the species as a function of soil water availability.

Using these data, we compared the behaviour of isolated plants, pairs and trios, and we found belowground competition to be a fundamental component of global (shoot + root) competition. Finally, our model suggests various circumstances that allow poor competitor plants to coexist in competition for water with more successful competitors. Apparently, this is not only due to transpiration rates, but also to differences in shoot emergence and shoot growth.
\end{abstract}

(C) 2009 Elsevier B.V. All rights reserved.

\section{Introduction}

In terrestrial plant communities, root competition is a ubiquitous process which plays a major role in determining interactions among individual plants and, consequently, shaping community structure and ecosystem functions. More than $70 \%$ of published root competition studies report significant interactions of this process with plant performance (Wilson, 1988; Coomes and Grubb, 2000).

Species composition affects the nature and intensity of root interactions in a plant community, and root interactions can, in turn, affect the diversity of local species through competitive exclusion, niche partitioning and facilitation. Root interactions are of primary interest when discussing the relationships between plant species diversity, ecosystem functions such as primary productiv-

E-mail addresses: josegsegarra@yahoo.es (J. Segarra), acevedo@unt.edu (M. Acevedo),jraventos@ua.es (J. Raventós),cgarcia@ula.ve, garcia7@fas.harvard.edu(C. Garcia-Núñez), jsilva@ula.ve (J.F. Silva).

${ }^{1}$ Current address: Biological Laboratories, Department of Organismic and Evolutionary Biology, Harvard University, 16 Divinity Street, Cambridge, MA 02138, USA. ity, and community invasibility (Wilson and Tilman, 2002; Cahill, 2003; Rajaniemi, 2003; Rajaniemi et al., 2003). Understanding such relationships requires a knowledge of plant interactions, of which root interactions are at least a major, and sometimes a dominant, component (Schenk, 2006).

In this paper, we present a theoretical stochastic model of root competition for water, which couples, soil water availability, phenology, and root and shoot architecture applied to three Neotropical savanna grasses. Soil moisture was simulated using a daily balance as proposed by Rodriguez-Iturbe et al. (1999). Finally, competition among neighbouring plants took into account the spatial distribution of the individuals.

We balanced gain (precipitation) and losses (percolation, evapotranspiration and runoff) using only vertical flows. Although this model does not account for explicit horizontal flow between contiguous soil columns, it has been shown that this simplification works equally well as more complex models that include this component (Guswa et al., 2002). Furthermore, the model implicitly incorporates a horizontal flow since in each iteration soil moisture is made equal throughout the area, taking into account water flows from higher to lower moisture content. 


\section{Nomenclature}

$a_{h}(i) \quad$ average leaf surface area per shoot $\left(\mathrm{m}^{2}\right)$

$b(s) \quad$ growth rate of new shoots $\left(\right.$ month $\left.^{-1}\right)$

$b_{\max } \quad$ growth rate of new shoots from water above $s^{*}$ (month ${ }^{-1}$ )

$B(x, y) \quad$ water demand for each point of coordinates $(x, y)$ due to all competing species $\left(\mathrm{cm} \mathrm{day}^{-1}\right)$

$B_{j}(x, y) \quad$ water demand from species $j$ at each point of coordinates $(x, y)\left(\mathrm{cm} \mathrm{day}^{-1}\right)$

$c \quad$ auxiliary variable (dimensionless)

$d(k) \quad$ number of days in month $k$

$D_{j}(x, y) \quad$ kernel of root density over space $x, y$, for species $j$

$E_{\max } \quad$ maximum evaporation rate $\left(\mathrm{cm} \mathrm{day}^{-1}\right)$

$E(s, t) \quad$ soil water loss rate by evaporation $\left(\mathrm{cm} \mathrm{day}^{-1}\right)$

$F \quad$ daily probability of a rainfall event $t_{d}(i)$ (dimensionless)

$g \quad$ parameter of Richard's equation (dimensionless)

$h_{\text {day }}(l)$ rainfall in a day $l\left(\mathrm{~cm} \mathrm{day}^{-1}\right)$

$H_{d}(k) \quad$ rainfall average for each rainy day in month $k$ $\left(\mathrm{cm} \mathrm{day}^{-1}\right)$

$H_{m} \quad$ mean monthly precipitation $(\mathrm{cm})$

$I(s, t) \quad$ soil infiltration rate $\left(\mathrm{cm} \mathrm{day}^{-1}\right)$

$J_{m} \quad$ average number of rainy days in each month (day)

$j_{m}(k) \quad$ frequency of rainy days in month $k$ (dimensionless)

$K_{s} \quad$ saturated hydraulic conductivity $\left(\mathrm{cm} \mathrm{day}^{-1}\right)$

$L(s, t) \quad$ soil water loss rate which includes deep percolation rate, transpiration and evaporation $\left(\mathrm{cm} \mathrm{day}^{-1}\right)$

$M(s, t) \quad$ soil water loss rate by leakage $\left(\mathrm{cm} \mathrm{day}^{-1}\right)$

$n \quad$ soil porosity (dimensionless)

$n_{h}(i) \quad$ number of shoots

$N \quad$ maximum number of shoots

$r \quad$ rate of change in number of shoots (month ${ }^{-1}$ )

$s \quad$ soil moisture (dimensionless)

$s_{f c} \quad$ soil field capacity (dimensionless)

$s_{h} \quad$ hygroscopic point, or soil moisture level below which water cannot be extracted from the soil through evaporation (dimensionless)

$s_{w} \quad$ permanent wilting point, or soil moisture level below which plants stop transpiring and begin to wilt (dimensionless)

$s^{*} \quad$ soil moisture level below which plants begin closing their stomata (dimensionless)

$t_{c} \quad$ constant rainfall threshold $\left(\mathrm{cm} \mathrm{day}^{-1}\right)$

$t_{\max }(i)$ maximum transpiration rate for species $i\left(\mathrm{~cm} \mathrm{day}^{-1}\right)$

$t_{\max }^{\prime}(i)$ transpiration capacity per unit of leaf surface for each species $\left(\mathrm{mmol} \mathrm{H}_{2} \mathrm{O} \mathrm{m}^{-2} \mathrm{~s}^{-1}\right)$

$T(s, t) \quad$ soil water loss rate by transpiration $\left(\mathrm{cm} \mathrm{day}^{-1}\right)$

$T_{\max } \quad$ average of maximum transpiration rates in modelled plants $\left(\mathrm{cm} \mathrm{day}^{-1}\right)$

$w_{i j}\left(x_{i}, y_{i}\right)$ root water uptake of each individual $i$ of species $j$ located in position $\left(x_{i}, y_{i}\right)\left(\mathrm{cm} \mathrm{day}^{-1}\right)$

$W_{j}(x, y)$ total root water uptake of species $j\left(\mathrm{~cm} \mathrm{day}^{-1}\right)$

$x \quad$ spatial coordinate $(\mathrm{m})$

$x_{i} \quad$ spatial coordinate of individual $i(\mathrm{~m})$

$y \quad$ spatial coordinate $(\mathrm{m})$

$y_{i} \quad$ spatial coordinate of individual $i(\mathrm{~m})$

$z \quad$ maximum distance at which soil humidity affects transpiration of an individual plant $(\mathrm{m})$

$Z_{r} \quad$ depth of soil $(\mathrm{cm})$

$\sigma_{a} \quad$ standard deviation of water absorption by plants

$\beta \quad$ parameter defining the exponential relationship between soil moisture and hydraulic conductivity (dimensionless)

$$
\begin{array}{ll}
\mu(s) & \text { mortality rate }\left(\text { month }^{-1}\right) \\
\mu_{\max } & \text { mortality rate as result of soil water content falling } \\
& \text { below } s_{h}\left(\text { month }^{-1}\right)
\end{array}
$$

We assigned a portion of soil moisture availability to each individual plant according to its rate of root absorption, which is directly dependent on the rate of shoot transpiration (Larcher, 2003). As a function of soil moisture availability, each plant could produce new shoots, grow them according to Richard's equation (Causton and Venus, 1981), or eliminate a fraction of the current shoots.

In previous research, we modelled the growth dynamics of Neotropical savanna grasses (Raventos et al., 2004; Segarra et al., 2005a,b), modelling competition as an interaction term parameterized by a coefficient, following the typical pattern of Lotka-Volterra models. Here, we went beyond the use of a coefficient and took a first step in formulating a process-based model, taking into account eco-physiology and root measurements. This model is able to provide a better explanation for the mechanics of water competition among savanna grass plants.

We centred the model on water, because competition interactions do not seem to change when soil fertility decreases (Tilman, 1982; DiTommaso and Aarssen, 1989; Wilson and Tilman, 1991; Silletti et al., 2004), although some studies point to a more complex relationship between water stress and competition ability (Chapin, 1980; Aerts and Chapin, 2000; Lambers et al., 1998, 2008). Furthermore, it has been argued that water is more important than nutrients on the whole below-ground competition process (Briguglio et al., 2000), as a shortage of water may kill the plants, but scarcity of nutrients only pushes plants to atrophy (Coomes and Grubb, 2000).

Our goals in this paper are to: (a) test our plant competition model against field measurements, and (b) test the often stated hypothesis (Casper and Jackson, 1997; Schenk, 2006), that belowground competition is more important than shoot competition for savanna grass ecosystems. Although we apply this model to some Neotropical savanna grasses, it can be easily transformed for use with different species and different grassland ecosystems. The use of stochastic- and spatial-dependent water competition models like these is a powerful tool in understanding and mitigating the effect of climate change on savanna ecosystems which can be affected by a decrease in rainfall precipitation (IPCC WGI Fourth Assessment Report, 2007, page 16, Figure SPM-7).

\section{Site and species}

This model is designed to simulate soil water competition among grass plants representative of the Neotropical savanna in Barinas, Venezuela $\left(8^{\circ} 38^{\prime} \mathrm{N} ; 70^{\circ} 12^{\prime} \mathrm{W}\right)$. This savanna shows high hydric seasonality, high evapo-transpiration rates, oligrotrofic soils and frequent fires. These conditions favour the presence of C4 grasses as a dominant vegetation. The mean annual temperature is $27^{\circ} \mathrm{C}$ and the average annual rainfall is $1250 \mathrm{~mm}$, with a wet season between May and November and a dry season from January to March. Fire often occurs at the end of the dry season. We tested our model on three perennial co-dominant grasses with different architecture and flowering phenologies: Elionurus adustus (Trin.) Ekman $(E)$, a precocious bunch grass species that flowers after the annual burning at the end of the dry season; Leptocoryphium lanatum (Kunth) Nees $(L)$, an early scleromorphic bunch grass that flowers in May, one month after the onset of rains; and Andropogon semiberbis (Nees) Kunth $(A)$, an erect late species that flowers in November. 
Table 1

Root extent $(\mathrm{cm})$ in three dimensions (average of six individual plants sampled per species). We use the word "length" as the horizontal dimension in which width of the root is greater, and we use the word "width" as the horizontal dimension perpendicular to the previous.

\begin{tabular}{llll}
\hline Dimension & A. semiberbis $(A)$ & E. adustus $(E)$ & L. lanatum $(L)$ \\
\hline$X$ axis (length) & Mean 36.5 std 9.11 & Mean 30.5 std 7.06 & Mean 20.3 std 4.63 \\
$Y$ axis (width) & Mean 29.2 std 7.96 & Mean 30.3 std 8.33 & Mean 18.7 std 6.28 \\
$Z$ axis (depth) & Mean 13.0 std 7.07 & Mean 13.2 std 4.45 & Mean 8.7 std 4.54 \\
\hline
\end{tabular}

\section{Material and methods}

To follow the evolution of tillers on these species in the field, we selected 21 individuals growing alone, in pair and trios, and counted the number of tillers on each individual during a year with a month periodicity (for details on these procedures see Raventós and Silva, 1988).

In order to select the appropriate spatial scale for the model, we excavated six plant roots for each species. As illustrated in Table 1, A. semiberbis, and $E$. adustus have similar horizontal root dimensions $(\sim 30 \mathrm{~cm} \times 30 \mathrm{~cm})$ and depths $(\sim 13 \mathrm{~cm})$, whereas L. lanatum tends to have a smaller root spread $(\sim 20 \mathrm{~cm} \times 20 \mathrm{~cm})$ and shallower $\sim 9 \mathrm{~cm}$ deep. The model distributes soil water among the species assuming that the soil is vertically homogeneous and that plant roots explore a space given by the dimensions shown in Table 1 .

Daily courses of transpiration rates were measured for each dry and wet seasons. From these different courses, mean values for the measured parameter for each season were obtained. Transpiration measurements were performed during rainfall season in 2006 (April 16-19) and during the dry season in 2007 (February 28 to March 3). A fully portable infrared gas analyzer unit, operating in open mode, was used to measure leaf gas exchange in the field ( $L C A-4, A D C$, Hoddesdon, England). Measurements were carried out on two fully expanded leaves from five different individuals, at $2 \mathrm{~h}$ intervals for each daily course. Gas exchange rates were determined for leaves sealed in the chamber for less than $30 \mathrm{~s}$, using calculations from von Caemmerer and Farquhar (1981).

\section{Soil water competition model}

As a first step in modelling the effect of soil moisture on the shoot performance of different phenological and architectural grass species, we built a mathematical model to simulate species growing in isolation, in pairs and in trios. In this model, each individual is situated at the centre of a $1 \mathrm{~m}^{2}$ surface and any neighbour at a distance of $5 \mathrm{~cm}$. The results of the model were compared with field data.

The simulated model followed the algorithm below (Fig. 1):

1. Soil moisture is determined as a function of a stochastic rainfall minus losses (interception, percolation, evaporation and transpiration).

2. Transpiration demand is calculated as a function of the number and surface area of leaves.

3. Water availability for transpiration is calculated from soil moisture, and the water distribution among neighbouring plants (taking into account the transpiration of each plant).

4. Rate of shoot formation and shoot mortality is calculated as a function of water availability.

5. The number of shoots of each plant is incremented, and the length updated according to Richard's equation. This step produces a change in the transpiration of each plant.

6. If the current simulated month is a fire-prone month (end of dry season), then there is fire-produced mortality of a fraction of the shoots. Therefore, each February, the model kills 90\% of the shoots of all species (Segarra et al., 2006).
Steps 1 and 2 were simulated with a daily periodicity, because rainfall and soil moisture may change significantly on a daily basis. Conversely, steps 3-5 were simulated on a monthly basis, since the number of shoots per plant does not change significantly throughout the month, but rather from one month to the next. Besides this, there was a lag between these changes and their effects on the plant. Consequently, daily simulation of steps 3-5 would slow down the simulation without significantly changing the output.

Finally, step 6 had an annual periodicity, to agree with savanna fire periodicity.

Fig. 2 shows views of the savanna in Barinas before (a) and after (b) the passage of fire. The latter shows the presence of several shoots reaching $10-20 \mathrm{~cm}$ high. Most of them will die in a few weeks.

\subsection{Daily soil moisture accounting}

We use a soil moisture balance equation as a difference between infiltration and loss rates

$n Z_{r} \frac{d s}{d t}=I(s, t)-L(s, t)$

where $n$ is the porosity of soil (dimensionless); $Z_{r}$ the depth of soil $(\mathrm{cm}) ; s$ the relative soil moisture content in relation to saturation level (dimensionless); $I(s, t)$ the soil infiltration rate $\left(\mathrm{cm} \mathrm{day}^{-1}\right)$; and $L(s, t)$ the soil water loss rate, which includes deep percolation rate, evaporation and transpiration $\left(\mathrm{cm} \mathrm{day}^{-1}\right)$.

Eq. (1) is similar to the one given in Laio et al. (2001).

We divided both the left- and right-hand side terms by $n Z_{r}$, the maximum quantity of soil moisture, to normalize the amount of soil moisture that can be held by the soil profile.

$\frac{d s}{d t}=\frac{I(s, t)}{n Z_{r}}-\frac{L(s, t)}{n Z_{r}}$

The soil water balance equation is solved on a daily time step.

The method of calculation for each term of Eq. (2) is shown below.

\subsection{Rainfall generator}

Infiltration rate is a fraction of daily rainfall determined by leaf interception and current soil moisture. We used daily precipitation data from the airport weather station in the State of Barinas,

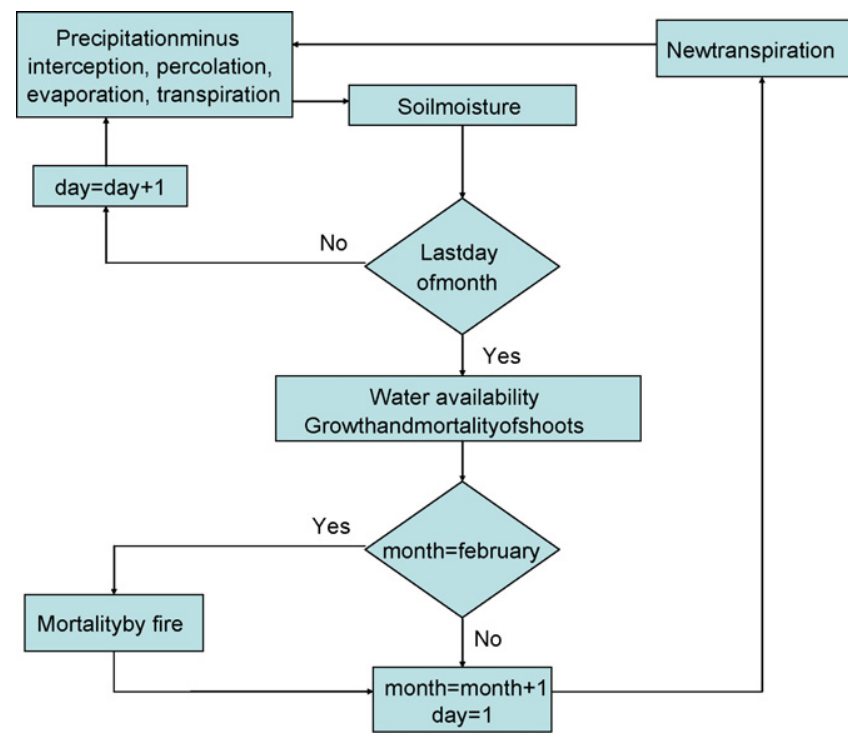

Fig. 1. Summarized structure and fluxes of the model, showing the three time scales: daily, monthly and yearly. 

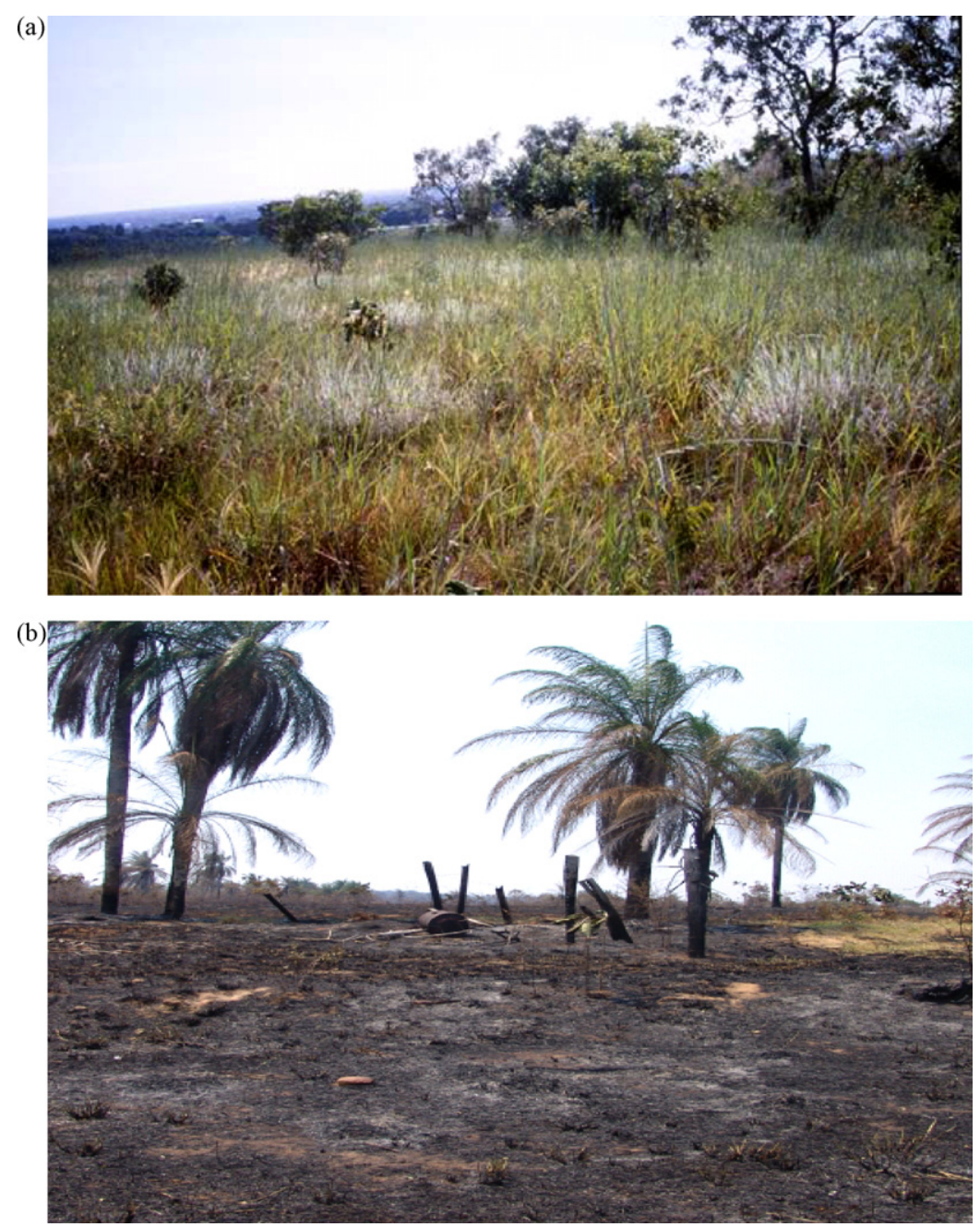

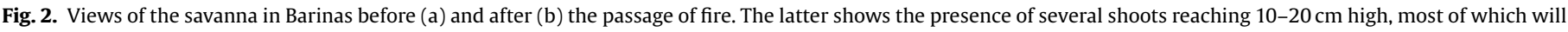
die in a few weeks.

Venezuela, for the period 1991-2007. This weather station is $3 \mathrm{~km}$ distant from the savanna field data, which were checked for homogeneity (Alexandersson, 1986).

In order to estimate the daily rainfall, $h_{\text {day }}$, we followed the schocastic procedure below:

1. First we calculated one vector with the mean monthly precipitation, $H_{m}$, in $\mathrm{cm}$ and another vector with the average number of rainy days per month, $J_{m}$, for the period 1991-2007.

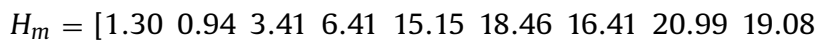

$12.47 \quad 8.35$ 2.05]

$$
J_{m}=\left[\begin{array}{llllllllllll}
4 & 5 & 6 & 7 & 10 & 11 & 12 & 14 & 15 & 12 & 12 & 9
\end{array}\right]
$$

2. We estimated the frequency of the rainy days in each month $k, j_{m}(k)$, as a ratio between the vector $J_{m}(k)$ corresponding to $k$ month and the number of days in each particular month, $d(k)$.

$$
j_{m}(k)=\frac{J_{m}(k)}{d(k)}
$$

3. The ratio between the vector $H_{m}(k)$ and $J_{m}(k)$ term for the same month, gives the average rainfall for every rainy day on the $k$ month, $H_{d}(k)$, in $\mathrm{cm} \mathrm{day}^{-1}$.

$H_{d}(k)=\frac{H_{m}(k)}{J_{m}(k)}$

4. For each day of the $k$ month, we generated a random number $r n 1$ uniformly distributed on $[0,1]$. If $r n 1>j_{m}(k)$, there is no precipitation and then $h_{\text {day }}(l)=0$, with $l$ being the day of the month $k$. Otherwise if $r n 1 \leq j_{m}(l)$, there is precipitation on the day, which can be calculated from step 5 of the above algorithm.

5. In order to estimate the amount of rainfall on the day, we generated another random number $r n 2$ uniformly distributed on $[0,1]$, and we also generated an exponential cumulative distribution function for each month according to the mean monthly precipitation.

$$
F=1-\exp \left(\frac{-h_{\text {day }}(l)}{H_{d}(k)}\right)
$$

where $F$ is the probability that on a $I$ day we would have a rain event $h_{\text {day }}(l)$ (dimensionless); $h_{\text {day }}(l)$ the amount of rainfall in a $l$ day $\left(\mathrm{cm} \mathrm{day}^{-1}\right)$; and $H_{d}(k)$ the average precipitation for each of the rainy days in a $k$ month $\left(\mathrm{cm} \mathrm{day}^{-1}\right)$.

6 . In order to calculate the $h_{\text {day }}(l)$ value, we replaced the $F$ parameter in the Eq. (3) by a second random number, $r n 2$, and we 


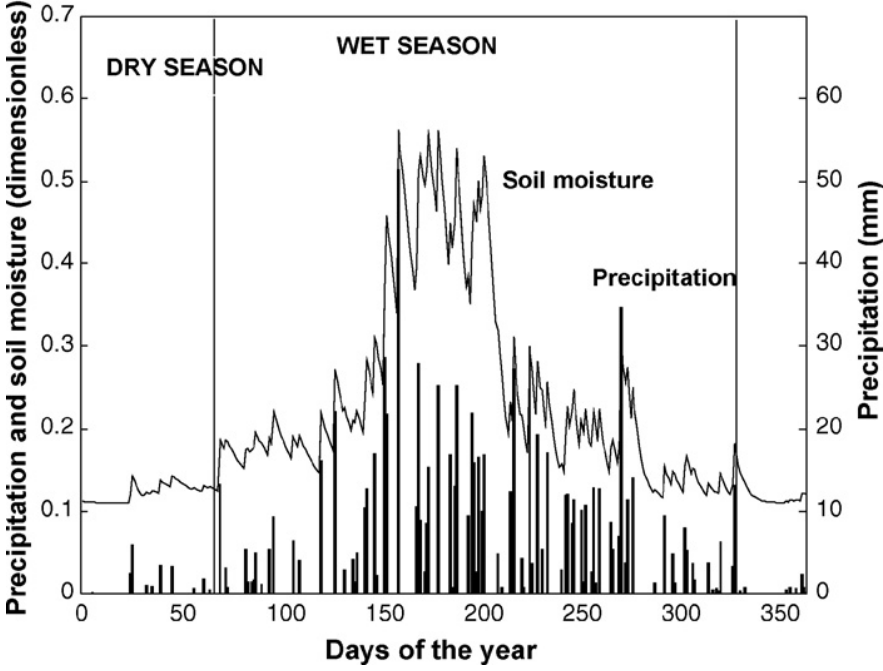

Fig. 3. Simulation of a rainfall event (solid bars) and soil moisture (continuous line) on relative basis during a year.

obtained

$$
h_{\text {day }}(i)=-H_{d}(k) \log (1-r n 2)
$$

Fig. 3 is an example of the stochastic simulation on the rainfall event and soil moisture throughout the year.

\subsection{Infiltration rate}

From the resulting amount of rainfall for the day, we subtracted a constant rainfall threshold, $t_{c}$, to account for the canopy interception parameter (Laio et al., 2001) and obtain the effective rainfall. In accordance with the Laio et al. (2001) savanna model, we assigned the value $0.05 \mathrm{~cm} \mathrm{day}^{-1}$ to this $t_{c}$ parameter. This is an arbitrary constant value, independent of rainfall event intensity, and it would need to be measured in the field. The infiltration capacity or maximum infiltration rate is given by the deficit $(1-s)$ times the soil storage capacity $n Z_{r}$.

If the value resulting from the subtraction for the current simulation day is less than zero, then the effective rainfall and infiltration are forced to zero. When the value of effective rainfall is less than the infiltration capacity $(1-s) n Z_{r}$, then the infiltration rate is set equal to effective rainfall; and when effective rainfall is greater than the capacity, the infiltration rate is set to capacity and the remainder of effective rainfall is assigned to runoff. All these conditions are summarized in the following equation.

$I(s, t)=\left\{\begin{array}{l}0 \text { for }\left(h_{\text {day }}(l)-t_{c}\right) \leq 0 \\ h_{\text {day }}(l)-t_{c} \text { for } 0<\left(h_{\text {day }}(l)-t_{c}\right)<(1-s) n Z r \\ (1-s) n Z r \text { for }\left(h_{\text {day }}(l)-t_{c}\right) \geq(1-s) n Z r\end{array}\right.$

where $\left(h_{\mathrm{day}}-t_{c}\right)$ term corresponds to effective rainfall.

Dividing by $n Z_{r}$ we obtain the normalized version

$$
\frac{I(s, t)}{n Z r}=\left\{\begin{array}{l}
0 \text { for }\left(h_{\text {day }}(l)-t_{c}\right) \leq 0 \\
\left(h_{\text {day }}(l)-t_{c}\right) / n Z r \text { for } 0<\left(h_{\text {day }}(l)-t_{c}\right) / n Z r<(1-s) \\
(1-s) \text { for }\left(h_{\text {day }}(l)-t_{c}\right) / n Z r \geq(1-s)
\end{array}\right.
$$

\subsection{Water losses from the soil}

In order to model the loss term $L(s, t) / n Z_{r}$, and according to Guswa et al. (2002), we took into account the losses by leakage $(M(s, t))$, evaporation $(E(s, t))$ and transpiration $(T(s, t))$.

$$
L(s, t)=M(s, t)+E(s, t)+T(s, t)
$$

Following Guswa et al. (2002), the above loss terms (7) can be put as a soil moisture function:

$M(s, t)=\frac{K_{s}\left(e^{\beta\left(s-s_{f c}\right)}-1\right)}{e^{\beta\left(1-s_{f c}\right)}-1} \quad s_{f c}<s<1$

$E(s, t)=\left\{\begin{array}{l}0 \text { for } 0<s \leq s_{h} \\ E_{\max } \frac{s-s_{h}}{s^{*}-s_{h}} \text { for } s_{h}<s \leq s^{*} \\ E_{\max } \text { for } s^{*} \leq s<1\end{array}\right.$

$T(s, t)=\left\{\begin{array}{l}0 \text { for } 0<s \leq s_{w} \\ T_{\max } \frac{s-s_{w}}{s^{*}-s_{w}} \text { for } s_{w}<s \leq s^{*} \\ T_{\max } \text { for } s^{*} \leq s<1\end{array}\right.$

where $K_{S}$ is the hydraulic conductivity at saturation $\left(\mathrm{cm} \mathrm{day}^{-1}\right)$; $\beta$ the parameter defining the exponential relationship between soil moisture and hydraulic conductivity (dimensionless); $s_{f c}$ the soil field capacity (dimensionless); $s_{h}$ the hygroscopic point, or soil moisture level below which water cannot be extracted from the soil through evaporation (dimensionless); $s_{w}$ the permanent wilting point, or soil moisture level below which plants stop transpiring and begin to wilt (dimensionless); $s^{*}$ the soil moisture level below which plants begin closing their stomata (dimensionless); $E_{\max }$ the

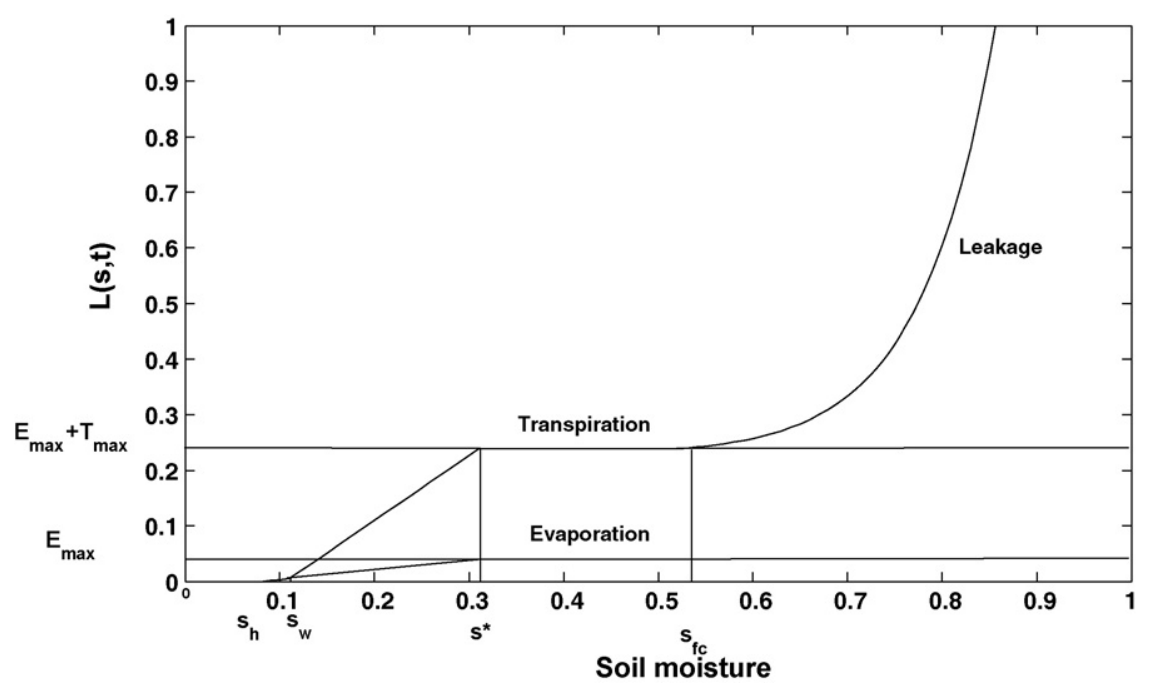

Fig. 4. Evolution of soil moisture as a function of water loss (leakage $(M(s, t))$, evaporation $(E(s, t))$ and transpiration $(T(s, t))$. This graph is a representation of the Eq. (7). 
Table 2

Soil characteristics.

\begin{tabular}{|c|c|}
\hline Texture & Loamy sand \\
\hline$n$ (porosity) & 0.42 (dimensionless) \\
\hline$Z_{r}$ (max depth of roots) & $30 \mathrm{~cm}$ \\
\hline$K_{S}$ (saturated hydraulic conductivity) & $100 \mathrm{~cm} \mathrm{day}^{-1}$ \\
\hline$s_{f c}$ (soil field capacity) & 0.52 (dimensionless) \\
\hline $\begin{array}{l}s^{*} \text { (soil moisture at which plants begin closing their } \\
\text { stomata) }\end{array}$ & 0.31 (dimensionless) \\
\hline$s_{w}$ (permanent wilting point) & 0.11 (dimensionless) \\
\hline$s_{h}$ (hygroscopic point) & 0.08 (dimensionless) \\
\hline $\begin{array}{l}\beta \text { (parameter defining curve of soil moisture and hydraulic } \\
\text { conductivity }\end{array}$ & 12.7 (dimensionless) \\
\hline
\end{tabular}

maximum evaporation rate $\left(\mathrm{cm} \mathrm{day}^{-1}\right)$; and $T_{\max }$ the maximum transpiration rate $\left(\mathrm{cm} \mathrm{day}^{-1}\right)$.

We have assumed soil evaporation to be constant in all the modelled surface. This surface is equal to $1 \mathrm{~m}^{2}$. We used a value of $0.02 \mathrm{~cm} \mathrm{day}^{-1}$ for $E_{\max }$ parameter, as given by Sarmiento (1984) for Neotropical savannas. This value is much lower that that given by Guswa et al. (2002), $\left(0.15 \mathrm{~cm} d a y^{-1}\right)$. This discrepancy is due to the fact that, in Neotropical savannas, evaporation is strongly limited. Fig. 4 illustrates the behaviour of losses as a function of soil moisture according to these equations. Table 2 displays the soil characteristics that we used, combining data from Laio et al. (2001) and Sarmiento (1984).

\subsection{Maximum transpiration per plant}

We first calculated the maximum transpiration rate for each species $i, t_{\max }(i)$, by measuring, in the field, the transpiration capacity per unit of leaf area $t_{\text {max }}^{\prime}(i)$ (in $\mathrm{mmol} \mathrm{H}_{2} \mathrm{O} \mathrm{m}^{-2} \mathrm{~s}^{-1}$ ) for each species (Table 3 ) and scaled by multiplying by an estimate of the leaf area of each individual (in $\mathrm{m}^{2}$ ). To estimate this leaf area, we multiplied the number of shoots by the average leaf area per shoot (Table 3 ). In short, to estimate $t_{\max }$ we used the following equation

$$
t_{\max }(i)=0.078 \times n_{h}(i) a_{h}(i) t_{\max }^{\prime}(i)
$$

where the constant 0.078 is to convert from mmol s${ }^{-1}$ to $\mathrm{cm} \mathrm{day}^{-1}$ (assuming $12 \mathrm{~h}$ of transpiration in a day); $n_{h}(i)$ is the number of shoots of the $i$ species; and $a_{h}(i)$ the average leaf surface area per shoot in the $i$ species $\left(\mathrm{m}^{2}\right)$ (Table 3$)$.

In the case of plant $A$, we had to multiply the value of Eq. (11) by 10 , because this plant had on average 10 leaves per shoot. With the other two plants, we did not make any correction because $E$ and $L$ had only one leaf per shoot.

\subsection{Soil water demand and availability}

In Eq. (10), the value of $T_{\max }$ for each plant is needed, whereas Eq. (11) gives $t_{\max }(i)$, which represents the maximum water transpired per individual $i$. These two values are not equal, because $T_{\max }$ depends not only on the transpiration from individual $i$ but also on transpiration from surrounding plants competing for water. Following Larcher (2003), we assumed that the root water uptake of each

\section{Table 3}

Daily transpiration rate (in $\mathrm{mmol} \mathrm{H}_{2} \mathrm{O} \mathrm{m}^{-2} \mathrm{~s}^{-1}$ ) measured in April, 2006, and average leaf surface area per shoot.

\begin{tabular}{llll}
\hline & A. semiberbis $(A)$ & E. adustus $(E)$ & L. lanatum $(L)$ \\
\hline$t^{\prime}$ max $\left(\mathrm{mmol} \mathrm{H}_{2} \mathrm{O} \mathrm{m}^{-2} \mathrm{~s}^{-1}\right)$ & & \\
Mean & 1.59 & 1.35 & 2.23 \\
Error & 0.21 & 0.67 & 1.19 \\
Max & 2.27 & 3.07 & 5.20 \\
$a_{h}\left(\mathrm{~m}^{2}\right)$ & & & \\
Mean & 0.01760 & 0.00099 & 0.00164 \\
\hline
\end{tabular}

Table 4

Kernel parameters.

\begin{tabular}{llll}
\hline & A. semiberbis $(A)$ & E. adustus $(E)$ & L. lanatum $(L)$ \\
\hline$\sigma_{x}(\mathrm{~cm})$ & 12.0 & 10.0 & 6.7 \\
$\sigma_{y}(\mathrm{~cm})$ & 10.0 & 10.0 & 6.7 \\
\hline
\end{tabular}

individual $i$ from species $j$, located in the position $\left(x_{i}, y_{i}\right)$ and denoted as $w_{i j}\left(x_{i}, y_{i}\right)$, is approximately equal to $t_{\max }(i)$. We also assumed that competition among neighbouring plants affects the amount of water in the soil (s), but not the efficiency of use of this water, thus making actual evapo-transpiration approximately equal to the real uptake, in accordance with the work of Melgoza et al. (1990) and Nippert and Knapp (2007).

$w_{i j}\left(x_{i}, y_{i}\right) \approx t_{\max }(i)$

\subsection{Spatial distribution}

To simulate soil water distribution among plants competing for this resource, we first defined a kernel, $D_{j}(x, y)$, of root density over space $x, y$ for $j$ species. We assumed that demand for water is greatest at the centre of the root mass and decreases further away from the centre. Thus, we defined this kernel as a Gaussian joint density function,

$D_{j}(x, y)=\frac{1}{2 \pi \sigma_{x} \sigma_{y}} \exp \left(-\frac{1}{2}\left(\frac{x}{\sigma_{x}}\right)^{2}-\frac{1}{2}\left(\frac{y}{\sigma_{y}}\right)^{2}\right)$

with parameters $\sigma_{x}, \sigma_{y}$ and centred on a point of coordinates $(0,0)$. This assumption is based on the notion that a normal would be a reasonable model in the absence of more precise information. We established the deviation parameters of the kernel by recalling that at $3 \sigma$ the density contains $99 \%$ of the mass. So, using the extent of root mass for all three species (Table 1 ) and by dividing by 3 we were able to assign values for the parameters (in $\mathrm{cm}$ ) given in Table 4 .

Secondly, we assumed that each individual plant collects all the water it requires from the point $\left(x_{i}, y_{i}\right)$ where it is located. Using the expression $w_{i j}\left(x_{i}, y_{i}\right)$ for individual water demand, we defined a function $W_{j}(x, y)$ which equals $w_{i j}\left(x_{i}, y_{i}\right)$ at the points where the modelled individuals of species $j$ are located, and equals zero in all other points. Total water demand $B_{j}(x, y)$ can then be found by calculating the convolution between $W_{j}(x, y)$ and its kernel of distribution $D_{j}(x, y)$

$B_{j}(x, y)=\int_{-\infty}^{\infty} \int_{-\infty}^{\infty} W_{j}(x, y) D_{j}\left(x^{\prime}-x, y^{\prime}-y\right) d x d y$

where $x^{\prime}, y^{\prime}$ refer to coordinates $x, y$ from the kernel of distribution.

We then calculated the total water demand $B(x, y)$ as the sum of the water demands from all $j$ species being modelled:

$B(x, y)=\sum_{j} B_{j}(x, y)$

Fig. 5 shows the graph of an unidimensional example of function B (total water demands) for some of the modelled cases. This illustrates the usefulness of the convolution technique to facilitate the estimation of moisture partitioning between neighbouring plants. Neighbour's water demands overlap; and plants with higher shoot density (and thus with higher transpiration rate) demand more water.

Finally, maximum transpiration for $i$ individual is the total water demand from the fraction of the surface surrounding this individual plant as follows,

$T_{\max }=\int_{x_{i}-z}^{x_{i}+z} \int_{y_{i}-z}^{y_{i}+z} B(x, y) d x d y$ 


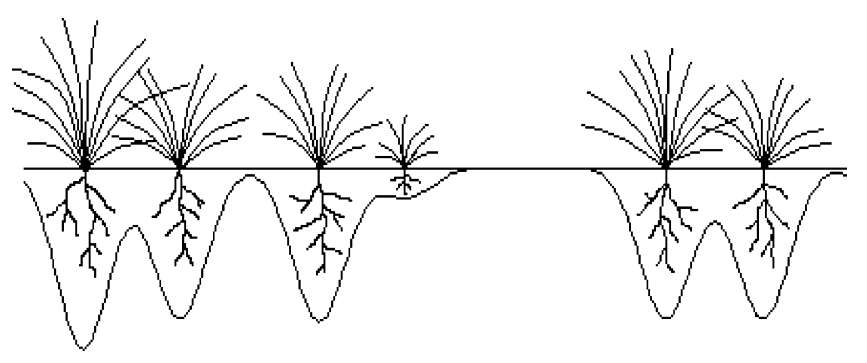

Fig. 5. A diagram representing the roots and shoots of the grasses. The line below is a representation of the kernel of water absorption by roots applied to all plants showing the pattern of absorption of soil moisture for the roots of the whole community.

where $z$ is the maximum distance at which soil humidity affects individual transpiration; here we used $z=0.5 \mathrm{~m}$ because at a greater depth, soil humidity was more stable and did not show the seasonal changes that appeared in the model (Sarmiento and Vera, 2003).

\subsection{Dynamics of shoots}

According to our previous work (Segarra et al., 2005b) the production of shoots is modelled by Richard's equation,

$\frac{d n_{h}}{d t}=\frac{r}{g} n_{h}\left(1-\left(\frac{n_{h}}{N}\right)^{g}\right)$

where $g$ is the coefficient controlling the shape of the function (dimensionless); $r$ the rate of shoots change $\left(\right.$ month $\left.^{-1}\right)$; and $N$ the maximum number of shoots.

The solution of (17) is given by

$n_{h}=N(1+\exp (c-r t))^{-1 / g}$

where $c$ is an auxiliary variable given by

$c=\ln \left(\exp \left(g \ln \frac{N}{n_{h}}\right)-1\right)$

Soil Moisture (dimensionless)
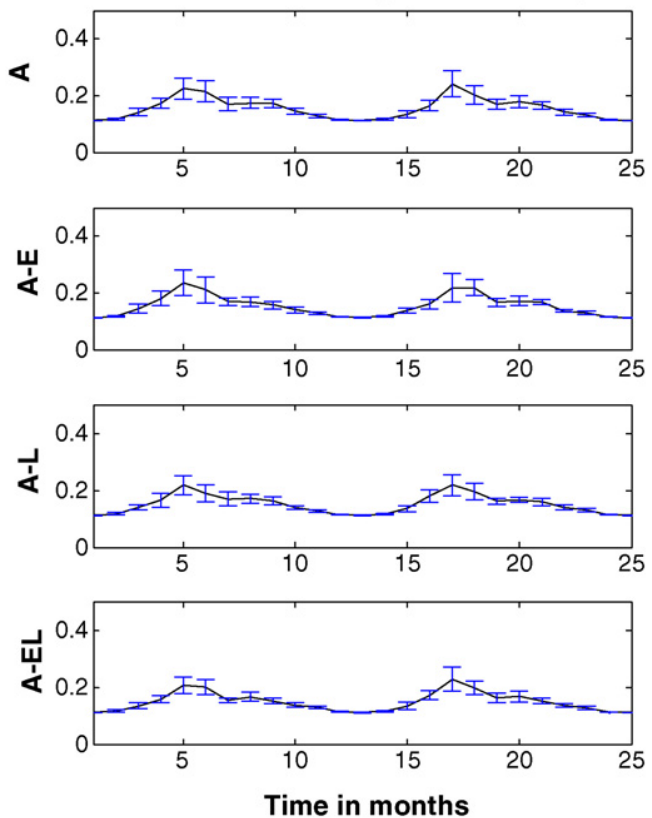

The simulation time for shoot dynamics is one month, because the increment in the number of shoots is calculated monthly, and the parameters for these equations were measured in the field with this periodicity.

We estimated $r$ in Eq. (17) as the difference between $b(s)$, shoot production rate, and $\mu(s)$, shoot mortality rate, both variables in month $^{-1}$ and both dependent on soil moisture,

$r=b(s)-\mu(s)$

To formulate how soil water availability affects formation and mortality rate we made the following assumptions.

1. When soil moisture is lower than the point below which plants begin closing their stomata $\left(s^{*}\right)$, shoot production rate starts to decrease linearly, becoming equal to zero when moisture reaches the wilting point $\left(s_{w}\right)$, according to the following equation:

$b(s)=\left\{\begin{array}{l}0 \text { for } s<s_{w} \\ b_{\max }\left(\frac{s-s_{w}}{s^{*}-s_{w}}\right) \text { for } \quad s_{w} \leq s \leq s^{*} \\ b_{\max } \text { for } s>s^{*}\end{array}\right.$

where $b_{\max }$ is the rate achieved for water above $s^{*}$.

This assumption results from the fact that, when the plant closes its stomata, photosynthesis is reduced and consequently the production of new biomass.

2. When the soil moisture drops below the wilting point $\left(s_{w}\right)$, mortality increases in proportion to the difference $\left(s_{w}-s\right)$ according to the following equation:

$$
\mu(s)=\left\{\begin{array}{l}
0 \text { for } s>s_{w} \\
\mu_{\max }\left(\frac{s_{w}-s}{s_{w}-s_{h}}\right) \text { for } \quad s_{h} \leq s \leq s_{w} \\
\mu_{\max } \text { for } s<s_{h}
\end{array}\right.
$$

where $\mu_{\max }$ is the mortality rate achieved for water below $s_{h}$.

Table 5 shows the value of the variables used in Richard's equation for the three species in the model. These values have been estimated from field data with plants growing in isolation.
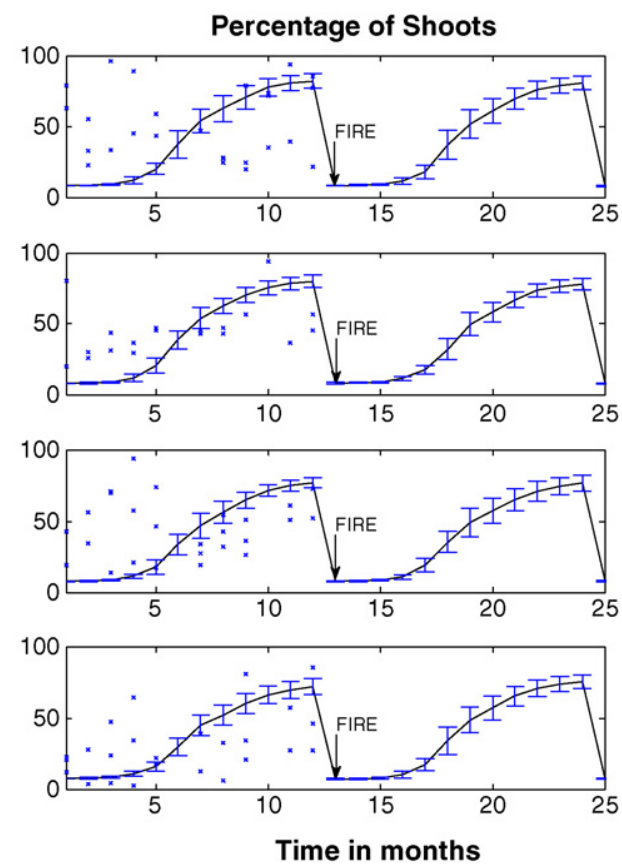

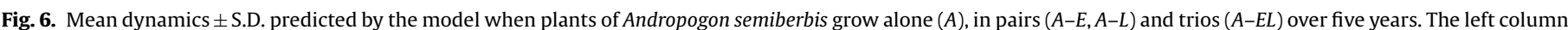
shows the evolution of soil moisture, and the right column the evolution of shoots. The crosses are the field data for the first 12 months for all combinations of species. 
Table 5

Parameters values for Richard's equation.

\begin{tabular}{lccc}
\hline & A. semiberbis $(A)$ & E. adustus $(E)$ & L. lanatum $(L)$ \\
\hline$g$ & 0.2 & 0.2 & 0.2 \\
$b_{\max }$ & 1 & 0.6 & 0.6 \\
$\mu_{\max }$ & 1 & 1 & 1 \\
$N$ & 110 & 850 & 360 \\
\hline
\end{tabular}

From Eqs. (2) and (18), we calculated the variations in water availability and number of shoots for the three species used in the model growing in isolation or in competition throughout the simulation period (Figs. 6-8).

\section{Results}

In this study, we modelled the growth of plants growing in isolation, in pairs and in trios, in order to compare the modelling results against field data. In future projects, we will model more complex communities made up of many individual plants over the spatial domain. In all cases, we ran the model 20 times, to estimate mean and coefficient of variation. Each run is for 17 years, but we have removed the first fifteen years to delete transient behaviour (Table 6).

Figs. 6-8 show, on the left-hand panel, the soil moisture for the plants studied, growing alone or in competition. Trends in soil moisture in these figures are in agreement with those measured in the field (Garcia-Nuñez, 2003).

The right-hand panel shows the number of shoots in percentage terms in relation to the maximum number $N$. These graphs also provide a graph of the number of shoots measured in the field (marked with crosses) to compare the model output with field data.

Contrary to the model output, the number of shoots measured in the field fluctuates considerably, possibly due to natural individual variability in the field, which is not included in the model. Furthermore, shoot numbers from the field following fire are much higher than those in the model because partially burnt shoots were taken into account despite the fact that they did not prosper (Fig. 2b). On the other hand, the model output slightly overestimates shoot numbers in the case of species $E$ competing with species $L$, and when species $A$ competes with the other two species, which may reflect the fact that the model does not consider any above ground competition. Nonetheless, the model produces a reasonable approximation to the growth in the field for both isolated and competing plants, and confirms that species $A$ is the least affected by interspecific competition, as shown in our field results. Overestimation of shoot numbers could be due to two factors: (1) the model does not include competition for light and (2) in the model mortality rate only starts when moisture falls below wilting point $\left(s_{w}\right)$.

Table 6

Mean square error between the model and data.

\begin{tabular}{llll}
\hline & Replicate 1 & Replicate 2 & Replicate 3 \\
\hline$A$ & 38.04 & 51.29 & 36.01 \\
$A E$ & 42.62 & 24.87 & No data \\
$A L$ & 64.51 & 40.82 & 30.57 \\
$A E L$ & 52.70 & 33.91 & 28.26 \\
$E$ & 26.17 & 23.03 & 33.90 \\
$E A$ & 16.81 & 25.75 & No data \\
$E L$ & 31.01 & 25.90 & 35.11 \\
$E A L$ & 11.85 & 18.62 & 12.85 \\
$L$ & 26.77 & 27.15 & 46.18 \\
$L A$ & 20.67 & 17.46 & 13.65 \\
$L E$ & 18.95 & 35.37 & 28.60 \\
$L A E$ & 17.79 & 15.00 & 12.88 \\
\hline
\end{tabular}

Figs. 7 and 8 show very similar trends, indicating that growth dynamics in species $E$ and $L$ are very similar both in the model and in the field. In the model, this similarity can be explained because total transpiration in the two species is about the same, despite the fact that transpiration rates in species $E$ is lower than in species $L$. But the foliar surface is larger in species $E$ because of the higher number of shoots. In addition, the parameters in the Richard's equation are the same for both species.

This fact can also be seen in Figs. 7 and 8; as competition increases, soil moisture decreases. We hypothesize that this is because transpiration increases as the number of plants in a location rises, but, unfortunately, we do not have field data to validate this result.

\section{Discussion}

1. In previous models we included competition as an explicit parameter whose value was estimated from field data, without any distinction between shoot $v s$ below-ground competition. In this model, competition is implicit as we model the effects of water partitioning between closely located plants on the changes in the number of shoots per plant. Therefore, this is below-ground competition, whereas shoot competition is not included either explicitly or implicitly. The fact that the model output adjusts reasonably well to the field data, with minor exceptions, supports the idea that below-ground competition is more important than shoot competition for grassy ecosystems (Casper and Jackson, 1997; Schenk, 2006).

2. The reasonable adjustment between the model output and the field data supports the initial idea that the convolution technique used in this model can be a powerful tool in modelling not only water absorption from the soil, but also the spatial distribution of other factors, such as shade or seed dispersal.

3. In agreement with the field data, the model output suggests asymmetric competition (Raventós and Silva, 1988). Our model shows species $A$ as a superior competitor to the other two species. It also shows that the soil dries faster in the locations where species $A$ grows, either alone or in competition. The effects of species $A$ on the growth of the other two species are much larger than the opposite effects of species $E$ or $L$ on the growth of species A. Studies of competition between Andropogon gerardii and Sorghastrum nutans (Silletti et al., 2004) showed an example of asymmetric competition with a high suppression effect by the former species, but an almost null suppression effect by the latter.

4. Our model suggests various circumstances that allow poor competitor plants to coexist in competition for water with better competitors. Some of those circumstances are: (a) removal of the aerial biomass of all herbaceous plants by seasonal fires (Collins, 1987; Vinton et al., 1993; Hartnett et al., 1996; Silletti et al., 2004); (b) colonization of empty spaces by poor competitors colonizing early in the growth season (Silletti and Knapp, 2001). This is clearly our case, as species $E$ and $L$ grow much earlier in the season than species $A$; and (c) partitioning of soil resources among competing plants (Nippert and Knapp, 2007), which in our case is evident in the various dimensions of roots we used to define the kernel of each plant (Table 1 ).

5. Our model allows the exploration of possible reasons as to why $A$ is a better competitor than the other two species. The most important reason is that this plant has the highest average leaf surface area per shoot, and, therefore, the largest transpiration surface. Another reason would be the differences in shoot emergence and shoot growth, since $A$ shows also the highest growth rate (Silva and Ataroff, 1985). 
Soil Moisture (dimensionless)
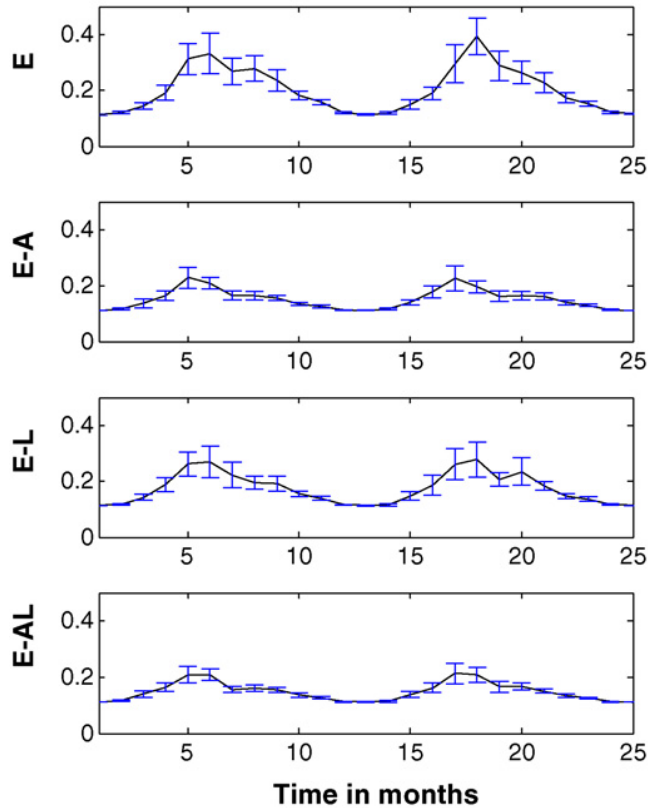

Percentage of Shoots
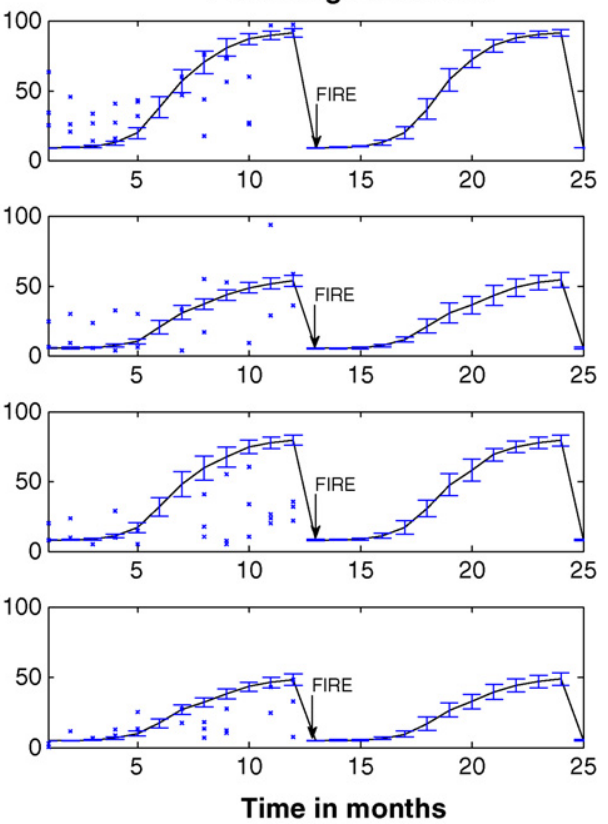

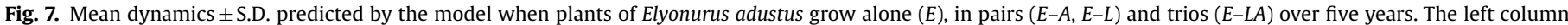
shows the evolution of soil moisture, and the right column the evolution of shoots. The crosses are the field data for the first 12 months for all combinations of species.

6. An interesting aspect of the model is that, according to parameter values taken from the literature (Laio et al., 2001), shoot mortality due to water deficiency starts when soil water goes below $11 \%$ (wilting point), and reaches a maximum when water is $8 \%$ (hygroscopic point). This implies that most mortality occurs in the narrow 3\% range. Since the IPCC 2007 projects possibly increase in dry conditions for these areas, environmental management should take into account this $11 \%$ critical threshold. Despite the fact that the number of tillers produced depends on a narrow range of soil humidity, our model mimics the mortality of tillers through water competition fairly well.
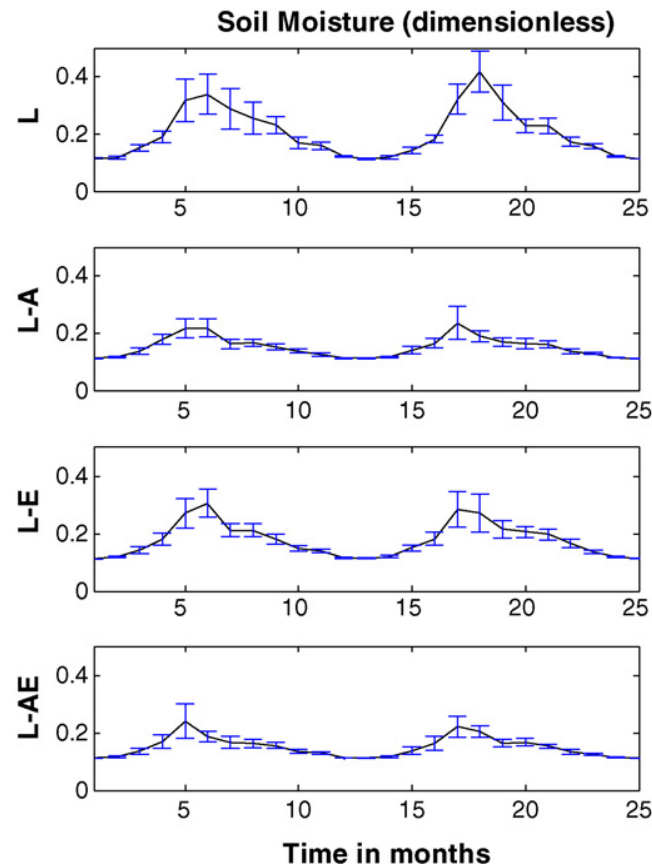

7. One limitation to our model is that the plant not only depends on the water absorbed by the roots at a given moment, but also on the water store in tillers and rhizomes. These organs could act as "capacitors" in the hydraulic circuit of plants and allow an extra supply of water (and carbohydrates) when water is not available in the soil. Differences in species regarding to this point could partially explain differences in the species of re-growth and formation of leaves before the rainy season.

Our next step will be to apply this model to a community of plants and include differential shoot growth rates depending on
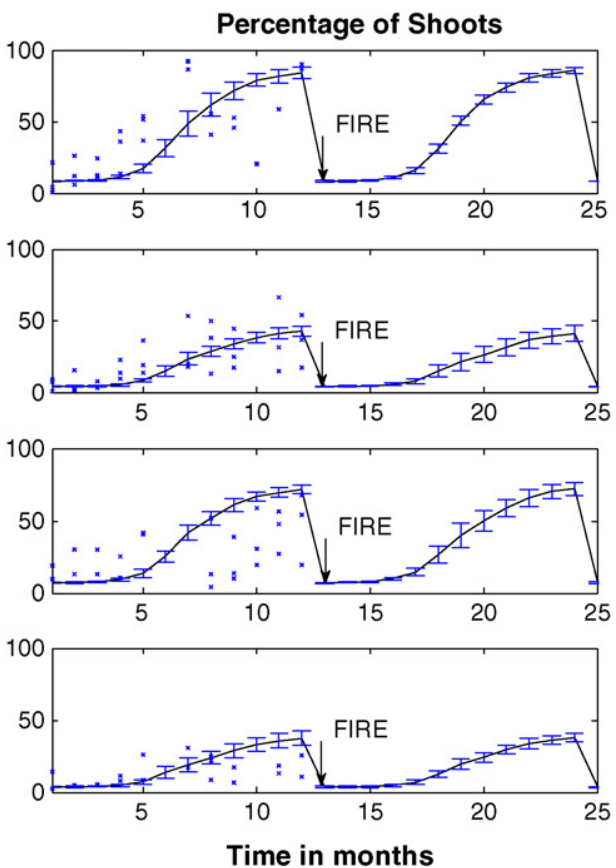

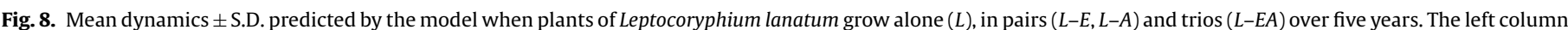
shows the evolution of soil moisture, and the right column the evolution of shoots. The crosses are the field data for the first 12 months for all combinations of species. 
eco-physiological factors, such as photosynthetic rates. In addition, we would like to include seed dispersal to take in to account not only growth dynamics, but also the whole dynamics of this ecosystem. Such modelling would allow us to explore savanna responses to the various scenarios of climate change.

\section{Acknowledgments}

We thank the Spanish Ministry of Education and Science (CGL2007-65315-C03_02; CGL2008-05112-C02-01/CLI) for their financial assistance. We also thank Elaine Rowe (B.A., DipTransIOL) for her linguistic revision.

\section{References}

Aerts, R., Chapin, F.S., 2000. The mineral nutrition of wild plants revisited: a revaluation of processes and patterns. Advances in Ecological Research 30, 1-67.

Alexandersson, H., 1986. A homogeneity test applied to precipitation data. Journal of Climatology 6, 661-675.

Briguglio, L., Janson, P., Oswald, L., 2000. Competition has a greater effect than supplemental nutrients on the growth of Sorghastrum nutans and Bromuskalmi. Tillers 2, 17-21.

Cahill Jr., J.F., 2003. Lack of relationship between below-ground competition and allocation to roots in 10 grassland species. Journal of Ecology 91 (4), 532-540.

Casper, B.B., Jackson, R.B., 1997. Plant competition underground. Annual Review of Ecology and Systematics 28, 545-570.

Causton, D.R., Venus, J.C., 1981. The Biometry of Plant Growth. Edward Arnold Ltd., London.

Chapin, 1980. The mineral nutrition of wild plants. Annu. Rev. Ecol. Syst. 11, 233-260

Collins, S.L., 1987. Interaction of disturbances in tallgrass prairie: a field experiment. Ecology 68, 1243-1250.

Coomes, D.A., Grubb, P.J., 2000. Impacts of root competition in forests and woodlands: a theoretical framework and review of experiments. Ecological Monographs 70, 171-207.

DiTommaso, A., Aarssen, L.W., 1989. Resource manipulations in natural vegetation: a review. Vegetatio 84, 9-29.

Garcia-Nuñez, C., 2003. Aspectos ecofisiologicos del estableciemiento de dos especies de arboles siempreverdes de las sabanas estacionales. Tesis Doctoral, Postgrado en Ecologia Tropical, Facultad de Ciencias, Universidad de Los Andes, Merida, Venezuela, 185 p.

Guswa, A.J., Celia, M.A., Rodriguez-Iturbe, I., 2002. Models of soil moisture dynamics in eco-hydrology: a comparative study. Water Resources Research 38 (9) 5.1-5.15.

Hartnett, D.C., Hickman, K.R., Fischer Walter, L.E., 1996. Effects of bison grazing, fire, and topography on floristic diversity in tallgrass prairie. Journal of Range Management 49, 413-420.

Laio, F., Porporato, A., Ridolfi, L., Rodríguez-Iturbe, I., 2001. Plants in water-controlled ecosystems: active role in hydrologic processes and response to water stress II. Probabilistic soil moisture dynamics. Advances in Water Resources 24, 707723.

Lambers, H., Chapin, F.S., Pons, T.L., 1998, 2008. Plant Physiological Ecology. Springer, p. 604.

Larcher, W., 2003. Physiological Plant Ecology, 4th ed. Springer, Germany.
Melgoza, G., Nowak, R.S., Tausch, R.J., 1990. Soil water exploitation after fire: competition between Bromus tectorum (cheatgrass) and two native species. Oecologia 83, 7-13.

Nippert, J.B., Knapp, A.K., 2007. Soil water partitioning contributes to species coexistence in tallgrass prairie. Oikos 116, 1017-1029.

Raventos, J., Segarra, J., Acevedo, M.F., 2004. Growth dynamics of tropical savanna grass species using projection matrices. Ecological Modelling 174, 85-101.

Raventós, J., Silva, J.F., 1988. Architecture, seasonal growth and interference in three grass species with different flowering phenologies in a tropical savanna. Vegetatio $75,115-123$.

Rajaniemi, T.K., 2003. Evidence for size asymmetry of belowground competition in press. Basic and Applied Ecology 4, 239-247.

Rajaniemi, T.K., Allison, V.J., Goldberg, D.E., 2003. Root competition can cause a decline in diversity with increased productivity. Journal of Ecology 91, 407-416.

Rodriguez-Iturbe, I., Porporato, A., Ridolfi, L., Isham, V., Cox, D.R., 1999. Probabilistic modelling of water balance at a point: the role of climate, soil and vegetation. Proc. R. Soc. London, Ser. A 455, 3789-3805.

Schenk, H.J., 2006. Root competition: beyond resource depletion. Journal of Ecology 94, 725-739.

Sarmiento, G., 1984. The Ecology of Neotropical Savannas. Harvard University Press, Cambridge, MA.

Sarmiento, G., Vera, M., 2003. La marcha anual del agua en el suelo en sabanas y bosques tropicales en los llanos de Venezuela. Agronomía Tropical 27 (6), 629-649.

Segarra, J., Raventós, J., Silva, J.F., 2005a. Modelling the effect of fire and competition on the dynamics of neotropical savanna: from plants to community. In: Proceedings of the fifth IASTED International Conference Modeling, Simulation and Optimization, Oranjested, Aruba, pp. 261-266.

Segarra, J., Raventós, J., Acevedo, M.F., 2005b. Growth of tropical savanna grass plants in competition: a shoot population model. Ecological Modelling 189, 270-288.

Segarra, J., Raventós, J., Acevedo, M.F., Silva, J.F., 2006. Modelling responses of savanna grass species to water supply and competition. In: Proceedings of the IASTED International Conference Environmentally Sound Technology in Water Resources Management, Gaborone, Botswana, pp. 11-16.

Silletti, A.M., Knapp, A.K., 2001. Responses of the codominant grassland species Andropogon gerardii and Sorghastrum nutans to long-term manipulations of nitrogen and water. American Midland Naturalist 145, 159-167.

Silletti, A.M., Knapp, A.K., Blair, J.M., 2004. Competition and coexistence in grassland codominants: responses to neighbour removal and resource availability. Canadian Journal of Botany 82, 450-460.

Silva, J.F., Ataroff, M., 1985. Phenology, seed crop and germination of coexisting grass species from a tropical savanna in western Venezuela. Acta Oecologica Oecologia Plantarum 6, 41-51.

Tilman, D., 1982. Resource Competition and Community Structure. Princeton University Press, Princeton, NJ.

Vinton, M.A., Hartnett, D.C., Finck, E.J., Briggs, J.M., 1993. Interactive effects of fire, bison (Bison bison) grazing and plant community composition in tallgrass prairie. American Midland Naturalist 129, 10-18.

von Caemmerer, S., Farquhar, G.D., 1981. Some relationships between the biochemistry of photosynthesis and the gas exchange of leaves. Planta 153, 376-387.

Wilson, J.B., 1988. Shoot competition and root competition. Journal of Applied Ecology 25 (1), 279-296.

Wilson, S.D., Tilman, D., 1991. Interactive effects of fertilisation and disturbance on community structure and resource availability in an old-field plant community. Oecologia 88, 61-71.

Wilson, S.D., Tilman, D., 2002. Quadratic variation in old-field species richness along gradients of disturbance and nitrogen. Ecology 83, 492-504. 